\title{
Communication
}

\section{Description of the Histological Features in Wounds of Snake Bite Aetiology}

\author{
Dissanayakalage Ajith Dissanayake ${ }^{1,3,}$, Cherine Susanthy Priyadharshini Sosai ${ }^{2}$, \\ Mawathagama Gedara Lional Weerawardane ${ }^{3}$, Jayavickrama Withanage Sriya Priyadharshanie ${ }^{3}$, \\ Rajapakse Peramune Vedikkarage Jayanthe Rajapakse ${ }^{1}$, \\ Senanayake Abeysinghe Mudiyanselage Kularatne ${ }^{4}$
}

${ }^{1}$ Department of Veterinary Pathobiology, Faculty of Veterinary Medicine and Animal Science, University of Peradeniya, Peradeniya, Sri Lanka ${ }^{2}$ Department of Pathology, District General Hospital, Gampaha, Sri Lanka

${ }^{3}$ District General Hospital, Gampaha, Sri Lanka

${ }^{4}$ Department of Medicine, Faculty of Medicine, University of Peradeniya, Peradeniya, Sri Lanka

\section{Email address:}

dajithd@gmail.com (D. A. Dissanayake), cherinesosai@yahoo.com (C. S. P. Sosai), lweerawardane@yahoo.com (M. G. L. Weerawardane), priyadharshaniejw@gmail.com (J.W. S. Priyadharshanie), jayanthar@pdn.ac.lk (R. P. V. J. Rajapakse),

samkul@sitnet.lk (S. A. M. Kularatne)

${ }^{*}$ Corresponding author

\section{To cite this article:}

Dissanayakalage Ajith Dissanayake, Cherine Susanthy Priyadharshini Sosai, Mawathagama Gedara Lional Weerawardane, Jayavickrama Withanage Sriya Priyadharshanie, Rajapakse Peramune Vedikkarage Jayanthe Rajapakse, Senanayake Abeysinghe Mudiyanselage Kularatne. Description of the Histological Features in Wounds of Snake Bite Aetiology. Advances in Surgical Sciences. Vol. 5, No. 4, 2017 , pp. 57-60. doi: $10.11648 /$ j.ass. 20170504.15

Received: February 21, 2017; Accepted: May 6, 2017; Published: August 3, 2017

\begin{abstract}
The chronic wounds that develop following snake bites may display a spectrum of histological features that could be correlated with the type of venom injected. The pathological changes may provide useful information for the management of chronic wounds that develop following snake bites. This study intends to assess the histopathological changes seen in chronic wounds following Daboia russelii (Russell's viper), Hypnale species (Hump nosed viper) and Naja naja (Cobra) bites and wounds of non snake bite aetiology. Inflammatory cells were seen in snake bite and non snake bite wounds. An intense mixed cellular inflammatory cell presence around the vessels could be seen. More lymphocytes and plasma cells were seen in wounds following snake bite and presence of more eosinophils was detected in wounds with other aetiology. Haemorrhagic areas in the dermis were seen in tissue samples taken from Naja naja and Hypnale species bite wounds. Vascular proliferation was predominant in all chronic wounds following snake bite. Granulation tissues were also more in chronic wounds following snake bites than the wounds of other aetiology. Among these three snake bites, haemorrhage was present mainly in Naja naja and Hypnale bite wounds compared to Daboia russelii.
\end{abstract}

Keywords: Histopathology, Chronic Wound, Russell's Viper, Hump Nosed Viper, Cobra, Aetiology

\section{Introduction}

Snakes are distributed in all over the world and snake bite has been an important topic of medical value since antiquity as it affects millions of generation annually. Most of the snakes are non venomous, venomous snake bite appear to be one of the neglected health problems of the tropical developing countries $[1,2]$.

Sri Lanka appears to be the richest country in herpetological wealth in South Asia. It's herpetofauna consists of nearly hundred amphibian and hundred and ninety reptiles, ninety six species are snakes $[1,3]$. In Sri Lanka the annual death rate 
due to snake bite envenoming is one of highest in the world categorization. But the treatment of snake bite patients has developed in good way over the past several decades and caused in a specific reduction in amount of deaths in the estate Hospitals [3, 4]. Among the venomous terrestrial snakes of the Sri Lanka especially four species of snakes are responsible for deaths, include namely Russell's viper, Cobra, Common krait and merrem's hump-nosed viper, On the other way non venomous and mildly venomous snakes are responsible for large amount of hospital admissions. These four highly venomous snakes are well known to produce local reactions at the bite site including, local swelling, bleeding from bite site and systemic effects like, coagulation defects and neurological effects. When comparing toxic effect of these venomous snakes in Sri Lanka, Common krait produce purely neuro toxic symptoms, Cobra cause neurotoxicity and severe local necrosis and Merrum's hump nosed viper produce severe local swelling and rarely renal failure $[1,4]$.

We concerned about comparison of different types of wounds following different types of snake bites with non snake bite etiology. Wounds following snake bite were not studied properly and with limited literature. So we planned to investigate chronic wounds following snake bite and their histological features. Further we compared them with wounds of non snake bite aetiology.

\section{Materials and Methods}

\subsection{Sample Selection}

Twelve primary tissue biopsy samples were obtained from chronic wounds for management purposes from patients admitted to surgical wards and surgical clinics of District General Hospital Gampaha Sri Lanaka.

These included chronic wounds of snake bite and non snake bite aetiology. There were three hump nosed viper (Hypnale) bite wounds, three russell's viper (Daboia russelii) bite wounds and three cobra (Naja naja) bite wounds. Three non snake bite aetiological wounds were also included. The possible aetiology of chronic wounds were elicited by clinical history.

\subsection{Method}

1. Tissue samples were transferred in to containers with $10 \%$ buffered formal saline for histopathological processing and examination.

2. Tissue fixed in $10 \%$ formal saline was processed by routine processing method of 18 hour duration using the graded alcohols, xylene and wax impregnation to tissue sections obtained at 4 micrometer thickness and then stained using haematoxylin and eosin

3. These tissue sections were used to assess the following histopathological features

(a). Type of chronic inflammatory cells identified included, plasma cells, lymphocytes, or eosinophils. The presence of these individual types of cells were graded as Grade I - less than 30 cells, Grade II less than 50 cells, and Grade III - more than 50 cells. These cells were assessed per 40 high power field (HPF).

(b). Presence or absence of granulation tissue.

(c). The intensity of endothelial / vascular proliferation Grade I - less than 5 capillary / lymphatic type vessels Grade II - less than 20 capillary / lymphatic type vessels and Grade III More than 20 capillary / lymphatic type vessels assessed per $40 \mathrm{HPF}$.

(d). The intensity of fibroblastic proliferation and the mitotic index in this areas were assessed - Grade I - less than 2 $\mathrm{X} 40 \mathrm{HPF}$ and less than $5 \mathrm{MF} / \mathrm{HPF}$ cells, Grade II less than $5 \mathrm{X}$ $40 \mathrm{HPF}$ and less than 20MF/HPF and Grade III - more than 5 $\mathrm{X} 40 \mathrm{HPF}$ and less than 50MF/HPF cells.

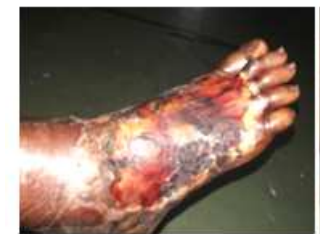

Hypnale

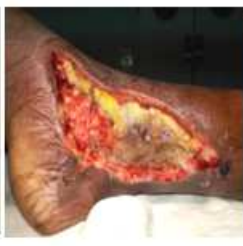

Naja naja

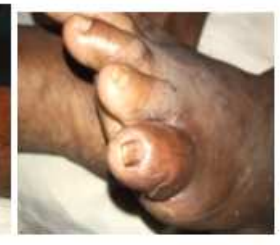

Daboia russelii
Figure 1. We selected more than one months old wounds following snake bites. On examination those wounds appeared non infected. Some wounds were subjected to wound toilets.

\section{Results}

The group of patients for this study was adults (more than 18 years) with wounds existing for more than one month of Russell's viper, Cobra and Hump nosed viper bites. They were compared with non snake bite aetiological wounds.
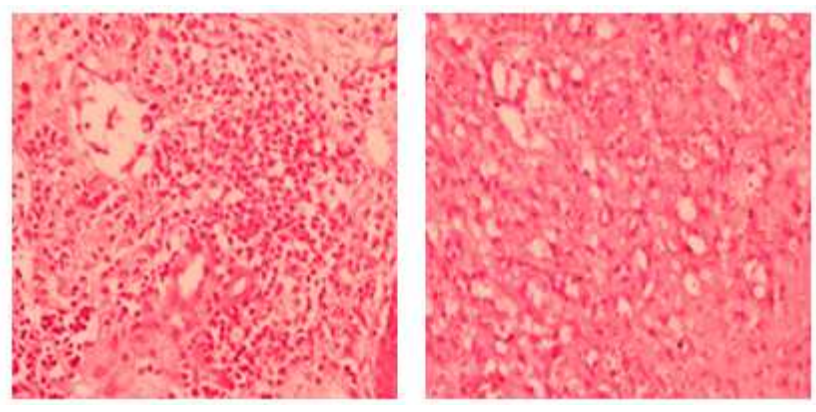

Figure 2. Marked cell infiltration with mix picture and inflammation around the vessels could be seen in all types of wounds.
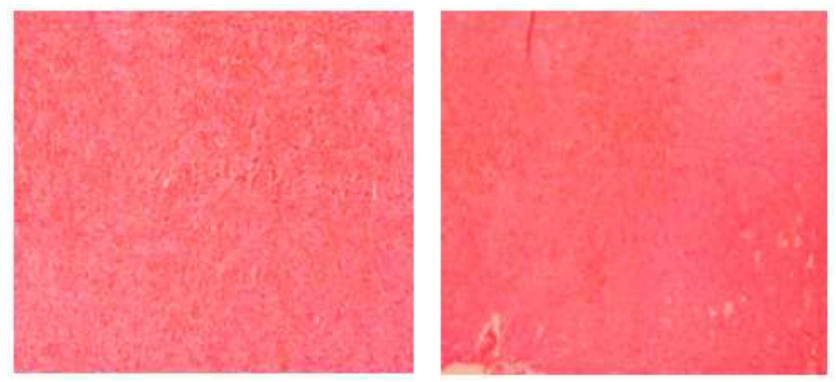

Figure 3. Hemorrhagic areas in hypodermis were seen in tissue sample taken from Najanajaand Hypnale species bite wounds. 
Table 1. Comparison of histological features in different aetiological wounds.

\begin{tabular}{lllllllll}
\hline Case & Oedema & Collagen Degeneration & $\begin{array}{l}\text { Inflammatory } \\
\text { Cells }\end{array}$ & Cell type & Haemorrhage & Vascularization & $\begin{array}{l}\text { Granulation } \\
\text { tissue }\end{array}$ & Mitosis \\
\hline Chronic wound & + & + & ++ & $\mathrm{L}>\mathrm{P}$ & + & +++ & + & - \\
Russells v & - & - & ++ & $\mathrm{P}>\mathrm{L}$ & - & +++ & + & - \\
Hump nosed v & - & - & ++ & $\mathrm{L}>\mathrm{N}$ & + & ++ & + & - \\
Najanaja & - & - & ++ & $\mathrm{N}>\mathrm{L}>\mathrm{E}$ & + & +++ & + & - \\
\hline
\end{tabular}

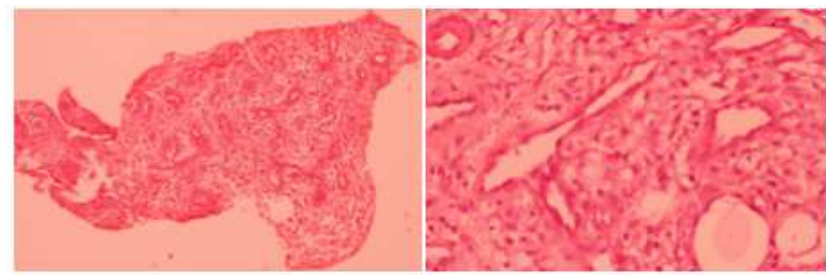

Figure 4. Vascular proliferation is more in chronic wounds following snake bite. Granulation tissues also more in chronic wounds following snake bites than the wounds of other aetiology.

\section{Discussion}

Tissue necrosis is more in snake bite following cobra (Naja naja) and Merrem's hump- nosed viper (Hypnale hypnale) in Sri Lanka. Wounds following snake bite [15] are also a significant health problem and related Histopathological studies also very rare.

Wound can adversely affect patient well-being, self-image, working capacity [5], independence and financial cost. Effective wound management is therefore necessary for both individual and the community $[5,6]$. Non- healing wounds are a major problem for health-care systems all over the world. In the industrialized world, about $1-1.5 \%$ of the population will have a problem wound at any time of life. Furthermore, wound management is expensive $[6,7]$. Wounds following snake bite is also a burden in the world $[8,9]$. Snake envenomation is an important public health problem in many tropical and subtropical countries and few attempts have been made to quantify the burden $[10,11]$. Russell's viper (Daboia russelii), cobra (Naja naja), common krait (Bungarus caeruleus), and Merrem's hump- nosed viper (Hypnale hypnale) are responsible for a significant number of deaths following snake bite envenoming in Sri Lanka [15]. Tissue necrosis is more in snake bite following cobra (Naja naja) and Merrem's humpnosed viper (Hypnale hypnale) in Sri Lanka. Wounds following snake bite [15] are also a significant health problem and related Histopathological studies also very rare.

When considering histopathological changes common to snake bite wounds of above mentioned types of snake, histological changes of snake bite wound with non snake bite wound aetiology found that, Collagen degeneration and Inflammatory cells were seen in all types of wounds. Marked cell infiltration with mix picture and inflammation around the vessels could be seen in biopsy tissue samples taken from chronic wounds following snake bite aetiology and Superficial dermal oedema couldn't be seen.

Haemorrhagic areas in hypodermis were seen in tissue sample taken from Naja naja and Hypnale species bite wounds. Vascular proliferation was predominant in all types of chronic wounds of these snake bites compared to chronic wounds of non snake bite aetiology.

\section{Conclusion}

Chronic wounds following snake bites found to have more granulation tissues and vascular proliferations than wounds of other aetiology. More Lymphocytes and Plasma cells were seen in wounds following snake bites and more eosinophils were detected in other aetiology. Among these three snake bites, more haemorrhages were present in Naja naja and Hypnale bite wounds compared to Daboia russelii. This study results will be helpful in identifying type of snake with the help of histopathologically in unknown snake bite cases.

\section{References}

[1] Kularatne SAM. Epidemiology and clinical picture of the Russell's viper (Daboiausseliiusselii) bite in Anuradhapura, Sri Lanka: A prospective study of 336 patients. Southeast Asian Journal of Tropical Medicineand Public Health 2003; 34: 85562.

[2] Warell DA. Animal toxins. In Manson's Tropical Diseases, eds. GC Cook and A Zumla, 21st edit. Saunders, London, 2003.

[3] Kularatne SAM, Ratnatunge N. Severe systemic effects of Merrem's hump-nosed viper bite. Ceylon Medical Journal 1999; 44: 169-70.

[4] Phillips RE, Theakston RDG, Warrell DA, Galigedara Y, Abeysekara DTDJ, Dissanayake P, et al. Paralysis, rhabdomyolysis and haemolysis caused by bites of Russell's viper (Vipera Russelli Pulchella) in Sri Lanka: failure of Indian (Haffkine) antivenom. Quarterly Journal of Medicine, New Series 1988; 68: 691-716.

[5] Graves, N. and Zheng, H., 2014. The prevalence and incidence of chronic wounds: a literature review. Wound Practice \& Research: Journal of the Australian Wound Management Association, 22(1), p. 4.

[6] Gottrup, F., Apelqvist, J. and Price, P., 2010. Outcomes in controlled and comparative studies on non-healing wounds: recommendations. J Wound Care, 19(6), pp. 237-268.

[7] Leach, M. J., 2004. Making sense of the venous leg ulcer debate: a literature review. Journal of wound care, 13(2), pp. 52-56.

[8] Sidgwick, G. P., Mc George, D. and Bayat, A., 2015. A comprehensive evidence-based review on the role of topicals and dressings in the management of skin scarring. Archives of dermatological research, 307(6), pp. 461-477. 
[9] Graves, N. and Zheng, H., 2014. Modelling the direct health care costs of chronic oundsin Australia. Wound Practice \& Research: Journal of the Australian Wound Management Association, 22(1), p. 20.

[10] Kasturiratne, A., Wickremasinghe, A. R., de Silva, N., Gunawardena, N. K., Pathmeswaran, A., Premaratna, R., Savioli, L., Lalloo, D. G. and de Silva, H. J., 2008. The global burden of snakebite: a literature analysis and modelling based on regional estimates of envenoming and deaths. PLoS Med, 5(11), p. e218.

[11] Brunda, G. and Sashidhar, R. B., 2007. Epidemiological profile of snake-bite cases from Andhra Pradesh using immune analytical approach. Indian journal of medical research, 125(5), p. 661.
[12] Nayak, B. S., Sandiford, S. and Maxwell, A., 2009. Evaluation of the wound-healing activity of ethanolic extract of Morinda citrifolia L. leaf. Evidence-Based Complementary and Alternative Medicine, 6(3), pp. 351-356.

[13] G. Pierce, Ph. D., MD, G. F. and Mustoe, MD, T. A., 1995. Pharmacologic enhancement of wound healing. Annual review of medicine, 46(1), pp. 467-481.

[14] Chereddy, K. K., Vandermeulen, G. and Préat, V., 2016. PLGA based drug delivery systems: Promising carriers for wound healing activity. Wound Repair and Regeneration, 24(2), pp. 223-236.

[15] W. Welton, R. E., Williams, D. J. and Liew, D., 2016. Injury trends from envenoming in Australia, 2000 - 2013. Internal medicine journal. 